\title{
A Clinical-Statistical Study on COVID-19 Cases in Iraq: A Case Study
}

\author{
Rasha Raheem ${ }^{1}$, Mohammed Kadhom ${ }^{2, *}$, Enas Zuheir Alhashimie ${ }^{3}$, \\ Wathik Abdul-Jabbar Alrubayee ${ }^{4}$ and Noor Albayati ${ }^{5}$
}

\author{
${ }^{1}$ Alkarkh Health Directorate, Baghdad, Iraq \\ ${ }^{2}$ Department of Renewable Energy, College of Energy and Environmental Sciences, Alkarkh University of \\ Science, Baghdad, Iraq \\ ${ }^{3}$ Department of Chemistry, College of Science, Al-Mustansiriyah University, Baghdad, Iraq \\ ${ }^{4}$ Alshifaa center, The Medical City, Baghdad, Iraq \\ ${ }^{5}$ Department of Science, College of Basic Education, University of Wasit, Azizia, Wasit, Iraq
}

\begin{tabular}{ll}
\hline \multicolumn{1}{c}{ Article's Information } & \multicolumn{1}{c}{ Abstract } \\
\hline Received: & Background: COVID-19 is a disease that started in Wuhan/China in late 2019 and \\
16.02 .2021 & continued through 2020 worldwide. Scientists worldwide continue to research to \\
Accepted: & find vaccines, treatments, and medication for this disease. Studies also conenue \\
01.03 .2021 & to find the pathogenicity and epidemiology mechanisms. \\
Published: & Materials and Methods: In this work, we analyzed cases obtained from Alshifaa \\
23.04 .2021 & center in Baghdad/Iraq for $23 / 2 / 2020-31 / 5 / 2020$ with total instances of 797, \\
Keywords: & positive cases of 393 , and death cases of 30. \\
COVID-19 & Results: Results showed that the highest infection cases were among people aged \\
SARS-CoV-2 & between $41-45$. Also, it was found that males' number of cases was more than \\
Cases distribution & females. In contrast, death cases were significantly higher in males than females. \\
Transmitted diseases & It was notable that the number of cases increased over time; here, it grew from \\
Pandemic & April to May from 92 to 238, respectively. \\
Epidemiology & Conclusion: It is worth mentioning that by the beginning of Jun, the number of \\
& cases has dramatically increased, and now more than $2 \mathrm{~K}$ points are recorded \\
\end{tabular}

DOI: 10.22401/ANJS.00.5.02

Corresponding author:makbq6@mail.missouri.edu,kadhom@kus.edu.iq

\section{Introduction}

COVID-19 is a disease that started in Wuhan/China in late 2019 and continued through 2020 worldwide. In the beginning, the virus's origin was not identified until January 2020, where a virus from the corona family was detected and named Severe Acute Respiratory Syndrome Coronavirus 2 (SARS-CoV-2). The coronaviruses appeared twice before the recent one in the last two decades, namely, Severe Acute Respiratory Syndrome SARS in 2002 and Middle East Respiratory Syndrome (MERS) in 2012. The virus is from the beta type of Corona viridae family, which has different types including: alpha-coronavirus, betacoronavirus, delta-coronavirus gamma corona virus well as several subgenera and species, with a very high infection rate [1]. The virus's symptoms vary from a patient to another, where some could show no symptoms at all, while others require intensive care and some of them face death. It was also found that the sickness severity and death cases in children and youngsters are less than other age categories. However, older people had the highest severity and death cases, particularly those with chronic diseases [2].

This virus's structure is similar to the previous coronaviruses. It consists of glycoproteins envelope with a spherical and halo-like shape. The envelope is a bilayer lipid-containing copied nucleocapsids attached to an RNA genome and taking a bead-string shape. The pins on the surface stick hardly on the human cells; hence, changes occur on the "cells" surface, and the virus membrane merges within the cell's one. Once the virus is in, it can copy itself and cause it [3, 4].

To control an epidemic, the effective reproductive (Rt) number, which is the number used to measure disease transmission potential, needs to be less than one [5]. Many protection ways were suggested to reduce that number, including wearing masks, washing and cleaning hands, and keeping a social distance. Other reasons could affect the transmission of the virus, such as air pollution, climate conditions, and other diseases [6]. This could explain the divergence in cases and fatality numbers from one region to another. Though, there is still a mystery in the viral behavior and the way of immunity response in humans.

On the other hand, it is known that some betacoronaviruses like OC43 and HKU1 to cause annual wintertime outbreaks of respiratory illness in temperate regions. This fact suggests that wintertime climate and host behaviors may facilitate transmission, although the 


\section{Al-Nahrain Journal of Science}

Special Issue: COVID-19, April 2021, pp. 6-12

COVID-19 seasonal effect still under investigation. Dissemination of MERS-CoV and SARS-CoV have also been associated with climate factors, possibly increased with lower temperatures and dry conditions [7-9].

Globally, the cumulative number of COVID-19 is over 49.7 million reported cases and over 1.2 million deaths since the start of the pandemic[10]. In Iraq, the first imported case was reported on February 24, 2020. The Iraqi authorities announced that an Iranian citizen, who entered Iraq before the Iraqi government decided to restrict Iranian citizens entry, was infected by coronavirus (COVID-19) [11].

This work analyzes the epidemiology status of the SARS-2 pandemic during the first term of the 2020 year in Iraq. The cases were low in number compared to other countries; and the tests were also low per day. The tests and cases were law also compare to the second half of the same year in Iraq. The study investigates the number of patents who came to one of the largest Iraqi centers in Bagdad. It is expected that this center's analytical results represent the overall COVID-19 status in Iraq. Knowing these statistics helps to anticipate the upcoming situations.

\section{Experimental}

Data were collected from Alshifaa center, located in the Rusafa side of Baghdad at the Medical City, which is the largest medical area in Iraq. These data were collected for all people who came to do the COVID-19 test, where some were diagnosed positively. Others were not from 23/February/2020 to 31/May/2020, with total cases of 797 . All cases were considered and classified based on age, gender, travel history, and nationality. Patients from different provinces aim at this place for other sicknesses. For statistical analysis, T-tests were used for the determination of statistical significance. $\mathrm{P}<0.05$ was selected as the level of significance. Data are expressed as means \pm S.E.M. In the figures section, data are displayed as Grouped -plot summary data and Column Scatter plot. All calculations were performed using Excel and Prism Plot Software.

\section{Results and Discussion}

From 23/February/2020 to 31/May/2020, 797 cases came to the Alshifaa center, 393(49.3\%) positive cases, and 30 $(3.8 \%)$ deaths. Data were analyzed as following:

\subsection{Age distribution}

Seven hundred ninety-seven patients came to the center with an age distribution peak from 20 years - to 60. Figure 1 shows the age categories of total cases tested for COVID19 in late February, including the positive and negative cases. March, April, and May 2020. The cases take the bell (natural distribution) shape. The number represents the people who are suspected of having COVID-19. The age distribution matches the global distribution of susceptible ages to get infected.

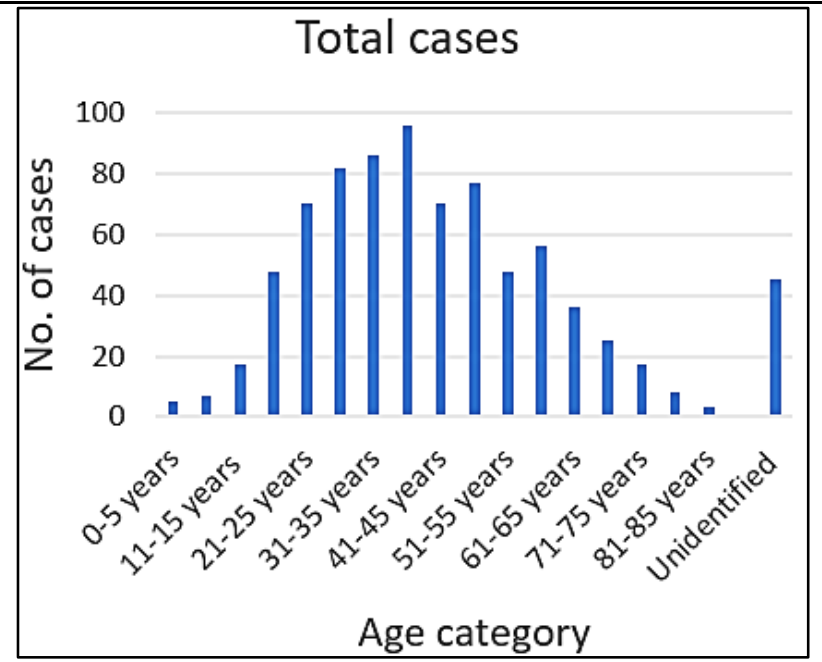

Figure 1. Total cases age distribution.

The distribution of positive cases has the same bell shape (natural distribution). Figure 2 shows the age distribution of positive cases. Patients in their 40s showed the highest rate of infection comparing to other age categories. This could be attributed to two reasons; first, the younger age categories could have less appeared symptoms and showed non. The second is older age categories, where their percentage to the younger age categories is less. Thus, lower numbers of elderly were recorded, while their rate is higher.

It has been shown that the children are less susceptible and less affected by COVID-19 than adults. They are more likely to have a mild or asymptomatic infection in, china population [12] and Europe [13]. The scientific explanation for target ages related to the difference in distribution, maturation, and functioning of viral receptors or immune imprinting by other viruses [14]. Research has shown that the functional receptor's expression for SARS-CoV-2, Angiotensin-converting enzyme 2 (ACE-2), within the nasal epithelium is lower in the lower age groups [15].

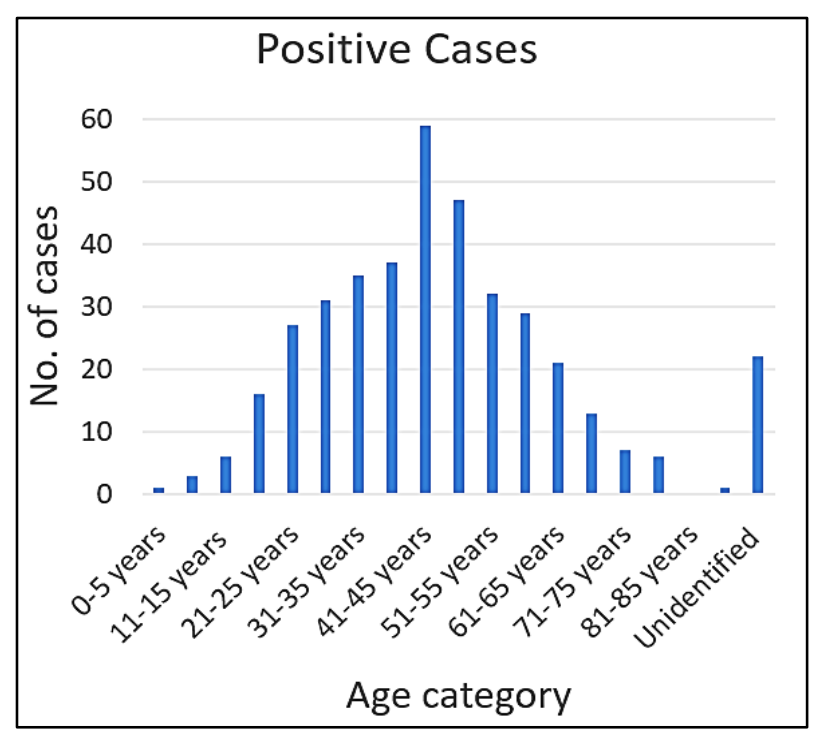

Figure 2. Positive cases age distribution. 


\section{Al-Nahrain Journal of Science}

Special Issue: COVID-19, April 2021, pp. 6-12

On the other hand, the highest age of death cases is showing in Figure 3, where it shows the highest death cases were among the late fifties age category. These results could be explained as this age category is considered a risk group age with chronic diseases and health problems [16]. It has been found that the most prevalent chronic diseases are hypertension, cardiovascular diseases, diabetes mellitus, smoking, chronic obstructive pulmonary disease, malignancy, and chronic kidney disease [17].

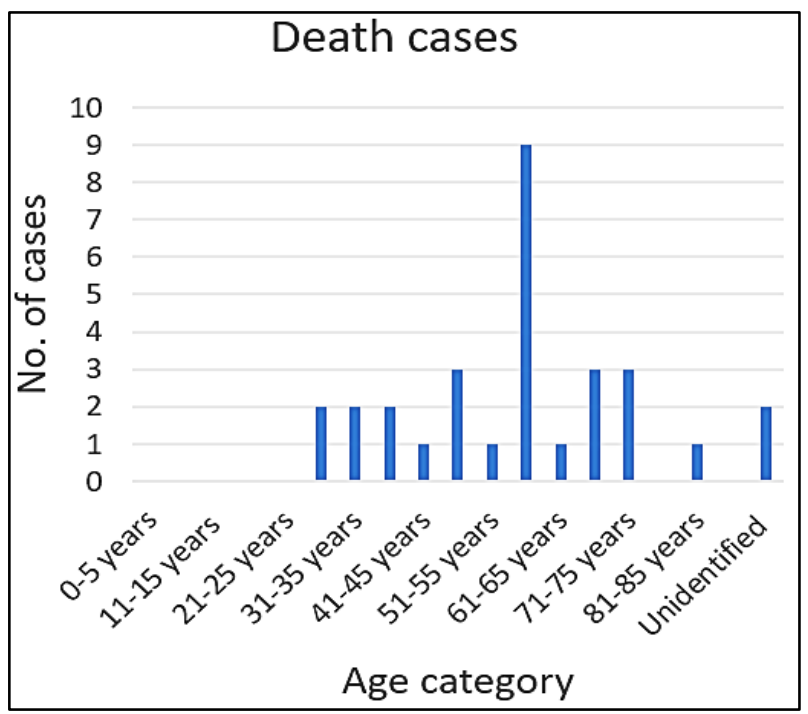

Figure 3. Death cases age distribution.

It is hypothesized that immunity against other species of SARS viruses like HCoV-NL63 and HCoVOC43 (nonSARS-HCoVs); that they body produce antibodies to spike protein (S protein) of CoVs. These antiboies have some degree of neutralizing and cross-protective activity against infection to another HCoV from the same group[18]. So, it is possible that high and sustained antibodies and immune reaction (seroconversion) toward the common none-SARSHCoVs, which a commonly infected pediatric population, may show protection against SARS-CoV-2. Hovi et al. confirm this hypothesis. The study showed that antibody titers to HCoV-OC43 increased rapidly up to age 14 years before tapering off and decreasing after age 60 years [19]. In summary, Children experience infrequent, mild, and selflimiting infections, and scientist refers that for many reasons: first, higher levels of cross-neutralizing antibodies; second, lower levels of ACE-2 receptors in the nasal epithelium, which lowers susceptibility to infection; third, immature $\mathrm{B}$ and T-cells and higher regulatory $\mathrm{T}$-cell response in childhood age; and finally, lower IL-6 and TNFa production, limiting inflammatory response [18]. On the other hand, adults may experience severe to deadly symptoms. The $\mathrm{S}$ protein enhances entry into cells via Fc receptors, resulting in cytokine storms, which cause severe lung injury. The elderly may be even more susceptible to COVID because they have more a fucosylated IgG [19], which has a higher affinity with Fc receptors. Another explanation is that the comorbidities in the elderly also result in upregulation of CD147, increasing viral entry and exacerbation of proinflammatory responses, which increase mortality risk [20].

\subsection{Gender distribution}

The 797 patients who came to the center divided into 457 $(57.3 \%)$ male and 311(39.0\%) female, and $29(3.6 \%)$ unidentified patients. Figure 4 shows the number of totals, positive and negative tests. From the model, the 'males' number was higher than females. This is applied to people who felt the symptoms and went to the center to check. This means that even for the negative COVID-19 tests, the other sessional illnesses, such as influenza, were higher in males than females.

Moreover, the positive case profile shaped the same as gender distribution. The positive number of males cases, $230(58.2 \%)$, was higher than females, 155 (39.2\%). Figure 5 shows the positive cases in both genders. Ten positive cases were unidentified.

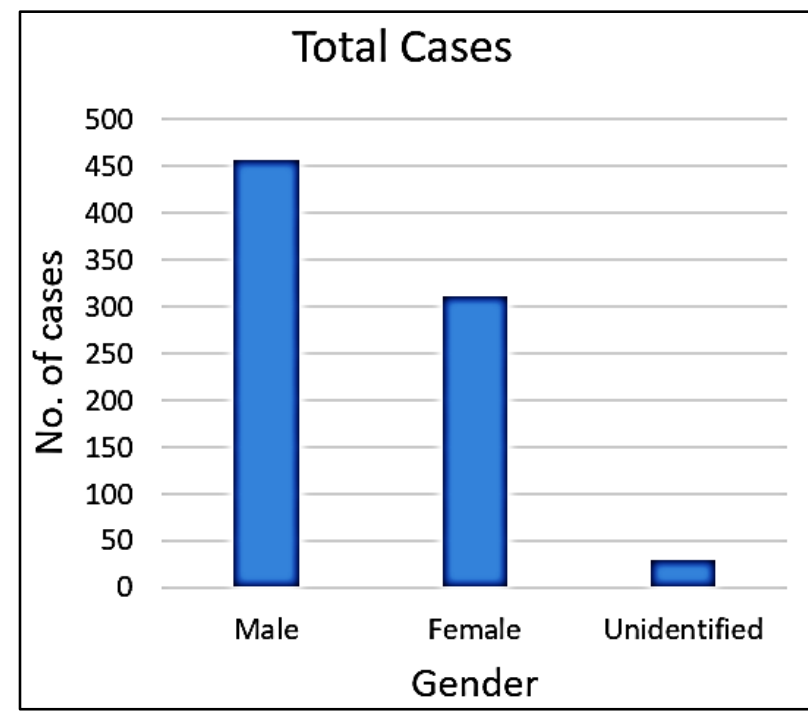

Figure 4. Total cases of gender distribution.

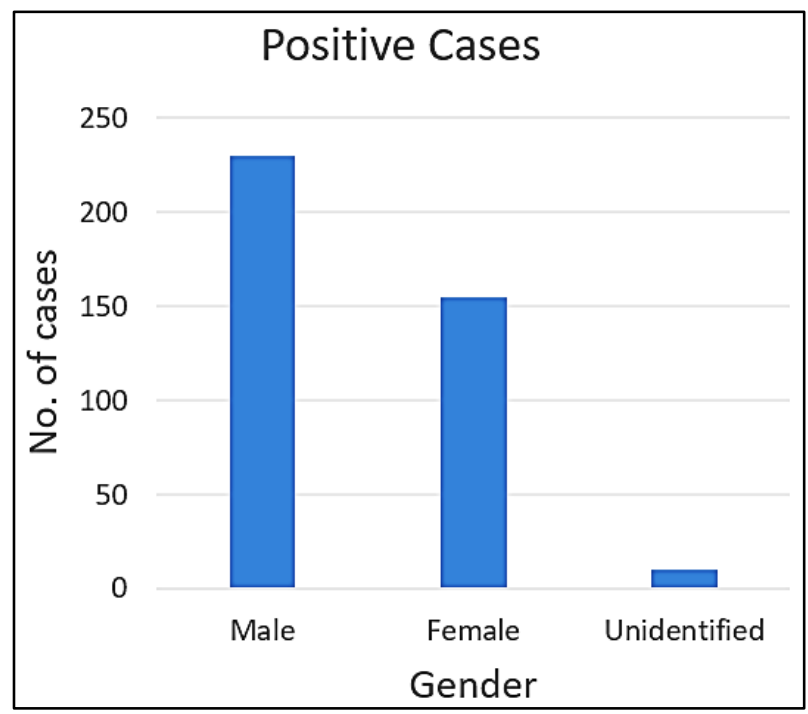

Figure 5. Positive cases gender distribution.

3.2.1 Death cases gender distribution 


\section{Al-Nahrain Journal of Science}

Special Issue: COVID-19, April 2021, pp. 6-12

Males showed a remarkably higher ratio of death cases than females. This was confirmed by other studies [6] and attributed to the sex hormones and genetic differences. The $\mathrm{X}$ chromosome and female hormones could result in estrogen receptors block and decrease the infection rate. Here, the coronavirus receptor (ACE 2) in men is affected by the hormones and 'men's lifestyle habits of smoking and drinking $[21,8]$.

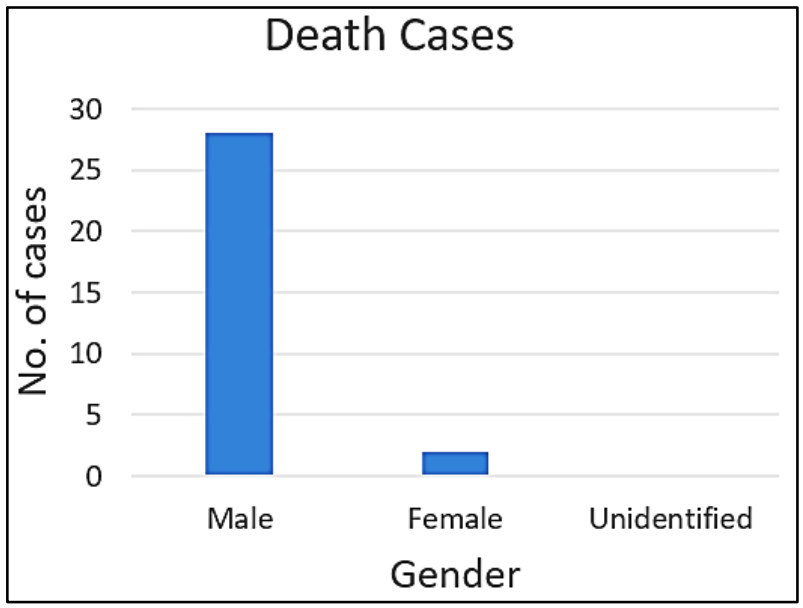

Figure 6. Death cases gender distribution.

\subsubsection{Female's age distribution of the total, positive, and mortality cases}

Figure 7 shows the 'females' total tests and positive cases. Both have the standard distribution shape, where the highest cases were among the middle age (30-50 years). The age category of 16-20 years total tests was 25 , though, six only were positive. The ratio of positive cases seems to be lower than in other classes. This shows that youngers get another sessional influenza that has similar symptoms to different age categories.

Moreover, Figure 7 shows the death cases, where only two female deaths occurred among 30 total patients.

\subsubsection{Male's age distribution of the total, positive, and mortality cases}

Figure 8 shows the total tests and positive cases of males, where these figures behave similarly to the "females" figures. It can be noted that the highest number of tests and positive cases were among people aged 36-40 years.

Figure 8 also shows the mortality among males, where no case under 25 years was recorded. However, in the age category 56-60 years, positive cases were 14, but 9 deaths were among them. This means that the death percentage was $64.3 \%$ in this age category, much higher than the normal ratio. There is no satisfying explanation for this finding.

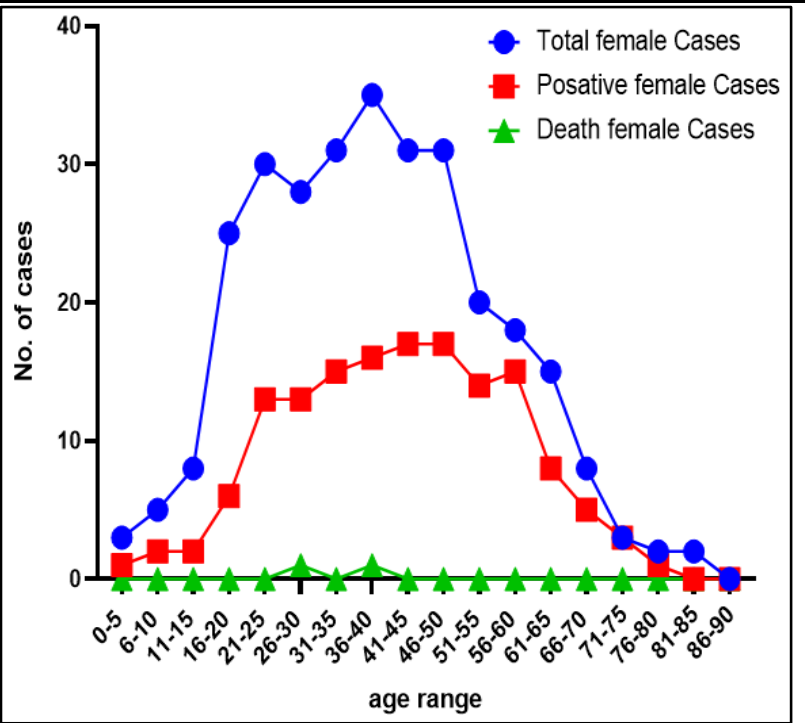

Figure 7. Female's age distribution show Total, Positive, and Death cases age distribution.

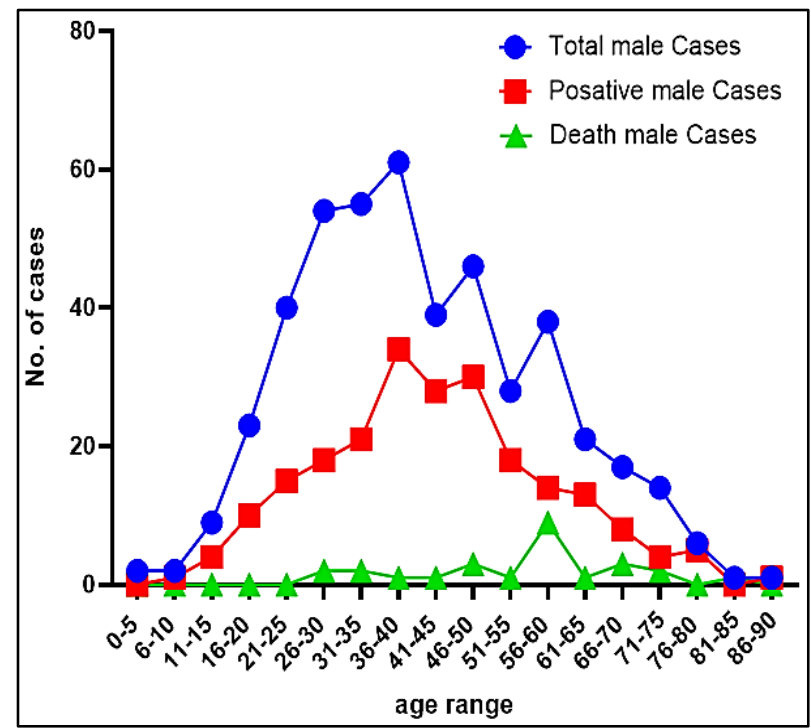

Figure 8. Males age distribution graph show Total, Positive and Death cases age distribution.

Iraq is not an exemption from the other countries. China was the first country who found gender distribution [15]. European countries, the USA, and other countries detect the same distribution [20]. These data were published from different hospitals and intensive care (ICU) centers.

SARS-Cov-2 should bind to the Angiotensin-converting enzyme (ACE) 2 receptor and the cellular serine protease TMPRSS2 to enter human cells [10]. ACE2 It is expressed on many cell's organs like The surface of lung alveolar epithelial cells, Enterocytes of the small intestine. Arterial and venous endothelial cells. Arterial smooth muscle cells of multiple organs [12]. ACE2 plays a crucial role in vasoconstrictor actions. ACE2 regulates cardiomyocyte's cellular biology, cardiac fibroblasts, and coronary endothelial cells in heart failure [7]. It has been found that 


\section{Al-Nahrain Journal of Science}

Special Issue: COVID-19, April 2021, pp. 6-12

ACE2 is higher in healthy, renal disease men, and diabetic men compared to women [19].

Besides, there is evidence that sex and sex hormones affect many components, including ACE2[11]. Moreover, ovariectomy increased ACE2 expression in the female kidney and adipose tissue, and estradiol replacement reduced ACE2 expression [14]. On the other hand, testosterone seems to maintain high ACE2 levels in the heart and kidney. In contrast, estrogen reduces ACE2 expression in these organs.

The last fact that TMPRSS2, which is the second protein necessary for SARS-CoV2 invasion into cells, is predominantly expressed in the prostate epithelium [17]. It is expressed several-fold higher in the prostate compared to other human tissue. All these sex differences in the immune system and hormones can explain the results that have been seen in the world between gender during corona.

\subsection{Total, positive, and death cases dates}

In Iraq, the first COVID-19 case was reported in late February. Here, we report the case numbers for the first three months of the global outbreak in Alshefaa center in Baghdad. The total tests were the same in March and April 203 patients came to the center in these months, followed by an increase in number where 371 came to do the COVID19 test. However, the positive cases started to increase gradually over time. The center reported 49 positive cases in March, 92 positive cases in April, and 238 positive cases in May. These numbers are summarized in Figure 9.

Figure 9 also shows the death cases numbers. However, the positive cases in April were almost double than those of March. The death cases were the same in both months, with eight deaths only reported. This could be attributed to the increase in 'weather's temperature and sunlight, where those highly deteriorate the virus [13]. The same conduct is shown in May; even total, positive, and death cases were higher than the previous months. It is good to mention that the death cases to positive cases ratio for March, April, and May were $16.3,8.7$, and $5.9 \%$, respectively.

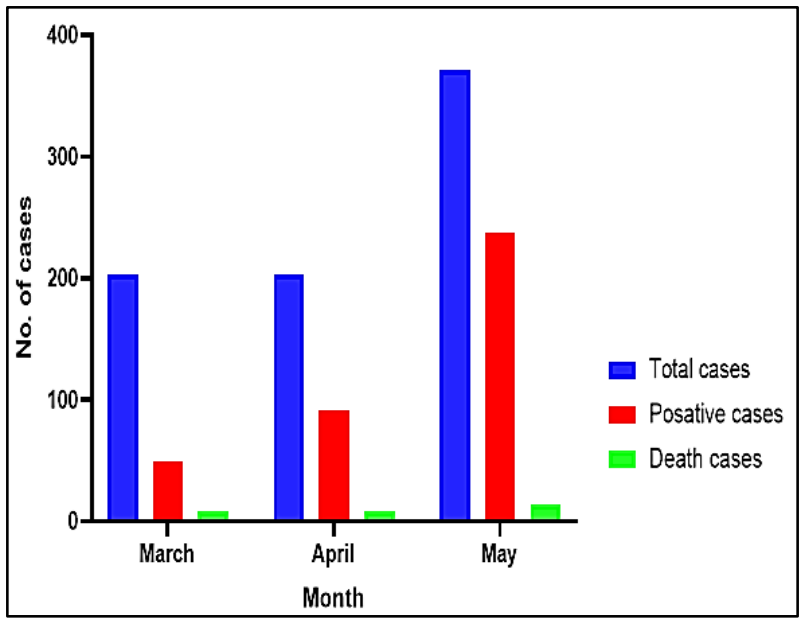

Figure 9. Alshefaa center cases distribution by month.
The figure show Total cases, Positive cases, and Death cases distribution based on check-in dates.

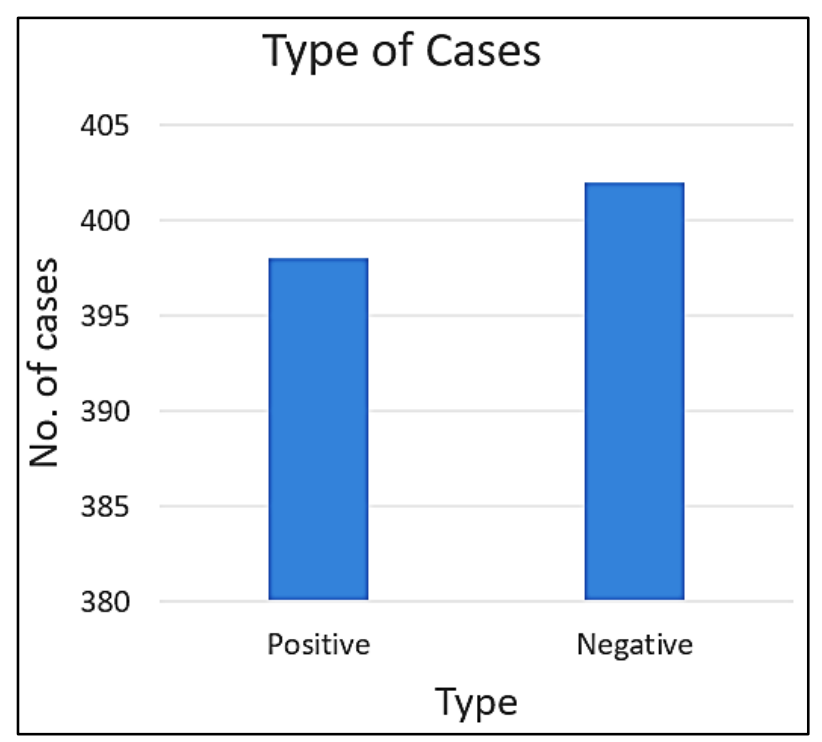

Figure 10. Type of cases.

\subsection{Other distributions}

\subsubsection{Total cases distribution}

Figure 10 shows the number of positive and negative tests, where they were almost equal. This could identify similar symptoms of other seasonal sicknesses.

\subsubsection{Nationality distribution}

Iraq is a close country; there is a small ratio of permanent international residents due to the wars and unstable situation. These residents are either come for service or diplomatic missions. Table 1 shows the cases numbers based on nationality.

\subsubsection{Travel history distribution}

Table 2 shows the travel history for people who took the test. The majority 'didn't travel, while a small portion traveled either to Iran or Turkey. Based on our experience here in Iraq, many patients didn't give the right answer about their travel history, so the number of people who traveled could be higher.

\section{Conclusion}

In this work, we show the history of coronavirus in Iraq, starting from late February 2020 until Jun's first. The data were obtained from Alshifaa center, located at the Medical City/Rusafa/Baghdad. During collecting these data, Iraq was run around 100 COVID tests per day compared to 2000 tests per day in late 2020. The number of infections and deaths has increased dramatically after Jun for many reasons. First, the test number per day increased, which means the capacity to detect the infection increased. Another reason could be the not following the curfew and quarantine instructions, not applying the social distance, and not wearing masks. Based on the data in this work, we 


\section{Al-Nahrain Journal of Science}

Special Issue: COVID-19, April 2021, pp. 6-12

can conclude that the peak of infected ages was the same as the other countries where the childhood age has no symptoms. Hence, the number of checked children was less, while we have the peak around the 40s and 50s. Another result is that the death to positive cases ratio was decreased by time. Females' death cases were much less than males, which could be attributed to the genetic influence and the higher responsibility that females showed than males to prevent the disease's spreading. Ultimately, this virus shows different symptoms in different patients, and there is no exact description for its activity yet. Here more researches and investigations are needed to come up with a comprehended description of the virus.

Table 1. Nationality of patients.

\begin{tabular}{||c|c|c|c||}
\hline Nationality & Total cases & $\begin{array}{c}\text { Positives } \\
\text { cases }\end{array}$ & $\begin{array}{c}\text { Deaths } \\
\text { cases }\end{array}$ \\
\hline \hline Iraqi & 784 & 395 & 30 \\
\hline Bangladeshi & 11 & 3 & 0 \\
\hline Kuwaiti & 1 & 0 & 0 \\
\hline Indian & 1 & 0 & 0 \\
\hline
\end{tabular}

Table 2. Travel history of patients.

\begin{tabular}{|c|c|c|c||}
\hline Country & Total cases & $\begin{array}{c}\text { Positives } \\
\text { cases }\end{array}$ & $\begin{array}{c}\text { Deaths } \\
\text { cases }\end{array}$ \\
\hline \hline Iran & 15 & 7 & 0 \\
\hline Turkey & 2 & 1 & 1 \\
\hline Didn't travel & 766 & 382 & 29 \\
\hline Unidentified & 14 & 5 & 0 \\
\hline
\end{tabular}

\section{References}

[1] Hadi A.; Kadhom M.; Hairunisa N.; Yousif E. and Mohammed S.; "A review on COVID-19: origin, spread, symptoms, treatment, and prevention", Biointerface Res. Appl. Chem. 10, 7234-7242, 2020.

[2] Alsayed R.; Kadhom M.; Yousif E. and Sabir; "An Epidemiological Characteristic of the COVID-19 Among Children”, Lett. Appl. Nano Bio Science, 9(3), 1156-1164, 2020.

[3] Leila M. and Sorayya G.; "Genotype and phenotype of COVID-19: Their roles in pathogenesis", J. Microbiol Immunol Infect. 10, 2020.

[4] Hamming I.; Timens W.; Bulthuis M.; Lely A.; Navis G. and van Goor H.; "Tissue distribution of ACE2 protein, the functional receptor for SARS coronavirus. A first step in understanding SARS pathogenesis", J. Pathol. 203(2), 631-637, 2004.

[5] Alsayed R.; Ali A.; Makia R.; Kadhom M.; Raheem R.; Al-Obaidi O.; Hadi A.; Sabir D. and Yousif E.; "Challenges Facing Iraq to Tackle the Spread of COVID-19: An Overview", J. Uni Anbar Pure Sci. 14(2), 22- 27, 2020.

[6] Chan K.; Malik Peiris J.; Lam S.; Poon L.; Yuen K. and Seto W.; "The effects of temperature and relative humidity on the viability of the SARS coronavirus", Adv. Virus, 2011(734690), 1-7, 2011.

[7] Gardner E.; Kelton D.; Poljak Z.; Van Kerkhove M.; von Dobschuetz S. and Greer A.; "A case-crossover analysis of the impact of weather on primary cases of Middle East respiratory syndrome", BMC Infect Dis. 19(1), 110, 2019.

[8] Lin K.; Yee-Tak Fong D.; Zhu B. and Karlberg J.; "Environmental factors on the SARS epidemic: air temperature, passage of time and multiplicative effect of hospital infection", Epidemiol. Infect. 134(2), 223-230, 2006.

[9] Hadi A.; Kadhom M.; Yousif E. and Hairunisa N.; "In COVID-19 time, how to protect myself and others? a review", Jurnal Biomedika dan Kesehatan. 3(3), 153$158,2020$.

[10] Al-Doori A.; Ahmed D.; Kadhom M. and Yousif E.; "Herbal Medicine as an Alternative Method to Treat and Prevent COVID-19”, Baghdad J. Biochem. App. Bio. Sci. 2(1), 1-20, 2021.

[11] Lee P.; Hu Y.; Chen P.; Huang Y. and Hsueh P.; “Are children less susceptible to COVID-19?”, J. Microbiol Immunol Infect. 53(3), 371-372, 2020.

[12] Bunyavanich S.; Do A. and Vicencio A.; "Nasal gene expression of angiotensin-converting enzyme 2 in children and adults", Jama, 323(23), 2427-2429, 2020.

[13] Zhou F.; Yu T.; Du R.; Fan G.; Liu Y. Liu Z,; et al.; "Clinical course and risk factors for mortality of adult inpatients with COVID-19 in Wuhan, China: A retrospective cohort study", The lancet. 395(10229), P1054-1062, 2020.

[14] Emami A.; Javanmardi F.; Pirbonyeh N. and Akbari A.; "Prevalence of underlying diseases in hospitalized patients with COVID-19: a systematic review and meta-analysis", Arch Acad Emerg Med. 8(1), e35, 2020.

[15] Dijkman R.; Jebbink M.; Gaunt E.; Rossen J.; Templeton K.; et al.; "The dominance of human coronavirus OC43 and NL63 infections in infants", J Clin Virol. 53(2), 135-139, 2012.

[16] Hovi T.; Kainulainen H.; Ziola B. and Salmi A.; "OC43 strain-related coronavirus antibodies in different age groups", J. Med Virol. 3(4), 313-320, 1979.

[17] Wong L.; Loo E.; Kang A.; Lu H.; Tambyah P. and Tham E.; "Age-Related Differences in Immunological Responses to SARS-CoV-2", J. Allergy Clin Immunol. 8(10), 3251-3258, 2020.

[18] Elgendy I. Y. and Pepine C. J.; "Why are women better protected from COVID-19: Clues for men? Sex and COVID-19”, Int. J. Cardiol. 315, 105-106, 2020.

[19] Guan W.; Ni Z.; Hu Y.; Liang W.; Ou C.; et al.; "Clinical characteristics of coronavirus disease 2019 in China”, N Engl J Med. 382(18), 1708-1720, 2020.

[20] Zhao S.; Cao P.; Chong M. K. C.; Gao D.; Lou Y.; et al.; "The time-varying serial interval of the coronavirus disease (COVID-19) and its gender- 


\section{Al-Nahrain Journal of Science}

Special Issue: COVID-19, April 2021, pp. 6-12

specific difference: A data-driven analysis using public surveillance data in Hong Kong and Shenzhen, China from January 10 to February 15, 2020", Infect Control Hosp Epidemiol. 41(6), 750-751, 2020.

[21] Hoffmann M.; Kleine-Weber H.; Schroeder S.; Kruger N.; Herrler T.; et al.; "SARS-CoV-2 cell entry depends on ACE2 and TMPRSS2 and is blocked by a clinically proven protease inhibitor", Cell. 181(2), 271-280.e8, 2020. 